\title{
REVIEW The Interpretative Route in News Production
}

JOSENILDO LUIz GUERRA

São Cristóvão: Editora UFS e Fundação Oviêdo

Teixeira, 2008

\section{Reviewed by Rogério Christofoletti}

A false dilemma exists among some journalism researchers: whether to reflect conceptually or propose new practices and procedures? That is to say, the frayed opposition of theory vs. practice. But this permanent tension is shown to be mistaken in more vigorous works such as that of Josenildo Luiz Guerra in O Percurso Interpretativo na Produção da Notícia (The Interpretative Route in News Production) (São Cristóvão: Editora UFS and Fundação Oviedo Teixeira, 2008).

The false dilemma is not diluted only by the complementary nature of the sides of the equation (theory and practice), but also by their inseparability. Guerra demonstrates this not only in the theorization on the bases of journalism, but also in the proposal for a reading of journalistic endeavor based on the practical knowledge of this activity. The author's final objective is clear from the beginning: to offer parameters for the evaluation of the quality of journalistic products. For this reason, he identifies a fundamental ethical imperative of the profession (the journalist needs to stick to the facts), and the conditions which sustain it (objectivity, neutrality, impartiality). Other pillars reinforce the edifice of journalism - truth and relevance - which Guerra deals with in detail and in a balanced way.

For the author, an essential aspect of journalistic activity is the interpretation of reality, a cognitive process which "guides and orients the treatment of the information obtained and processed during the production in journalistic organizations" (p. 111). Guerra gives the name of "Interpretative Route" to this cognitive process, whose analysis allows the viewing of the journalistic work in the process of its production, both from the professional's perspective as well as in its development inside the information media. This is one more characteristic of 
Josenildo's work: his attention to the engineering which moves the journalistic organizations, the management of the professionals and the accompaniment of the production stages. From this there derives a concern of the author for notions such as "coverage program", "reference news-values" and "coverage matrix". After all, it is in the organizations" environment that reporters, editors and publishers would apply the cognitive techniques in the generation of the interpretative route.

Tied to this route are competencies which function as prior knowledge necessary for journalistic activity. Thus, the professionals must not only know the facts, but also know how to act with the other factors involved in the news story and know how to transform data into journalistic accounts.

In the evaluation of journalistic work, two other concepts come into play: Quality and Performance. Quality should be understood as the adaptation to standards previously defined by the journalistic organization and the fulfillment of the expectations of the consumers of the information. Performance is the measurement of the work carried out, and the closer one gets to the sought-after quality, the better this performance will be. Aligned with it are also notions dear to the management, but which, regardless of the production sector, are more and more invoked: efficiency and effectiveness. In $O$ Percurso Interpretativo na Produção da Notícia, the ideas fit together well, they make up a woof, a latticework.

One observation justifies a pause in this review: how the author formulates his thesis. Methodical in his preparation and rigorous in his reasoning, Guerra constructs a consistent theory at the same time that he keeps his eye on journalistic practice. For this purpose, he puts into position one concept shored up by another, as if he were staking out a construction site, with beams and rods. In this connection, the metaphor which places the book in a position similar to that of a civil engineering work takes on new strength: there is a structure (of concepts) which provides rigid support for a well-defined purpose: to present a model applicable to the evaluation of journalistic quality. The reader moves on in the pages, like someone who goes down in an elevator and finds himself surrounded by a complex conceptual network which is revealed in layers, at increasingly deeper levels. The daily practice in the editorial offices is then scanned from Josenildo Guerra's perspective, extracting from it the dimensions which are decisive for measuring the results of journalistic work.

Divided into two parts, the book offers four initial chapters 
which are clearly basic. They are the foundations underlying the work. In the next eight sections, the author is concerned with erecting one wall at a time bringing their edges together, plastering over their corners. In this way, he not only systemizes his concept of route in terms of cognitive techniques of process and content, but he also penetrates into the workings of the journalistic organization. With this, Josenildo Luiz Guerra presents matrices which enable one to analyze the internal dynamics of a journalistic organization, its context and its environment of tasks, on one hand, and makes it possible to understand how audience expectations are formed with relation to the journalistic products, on the other. Attentive and coherent, the author emphasizes the idea that quality in journalism is the encounter of the adaptation to the standards of excellence predetermined by the communication companies with the satisfaction of the desires and requirements of the media public. It seems logical, but to discern this convergence of factors in everyday journalistic practice requires a level of detailing in the description of the stages which shows a great complexity of the situation encountered. Faced with this complexity, Guerra has recourse to tables, controls and organization charts duly borrowed from the Administration area and which are very welcome in the proposed analysis. Many journalism researchers would turn up their noses at a task like this one. The author met the challenge, since a building cannot be built without the knowledge of Engineering. How can one evaluate the management of the production and quality processes inside the journalistic organization without studying Administration? Beyond the difficulties, in the interface of different fields of knowledge there resides innovation and the scientific disposition to achieve comprehension of the phenomena and to propose parameters for evaluation.

With O Percurso Interpretativo na Produção da Notícia, Josenildo Luiz Guerra effectively contributes to the theories of journalism, to the criticism of journalism and to the quest for its improvement. Definitely, it is not any construction whatsoever.

Rogério Christofoletti is a journalist and Doctor in Communication Sciences. He is a professor in the Journalism Department of the Federal University of Santa Catarina, the author of books and articles on journalism, ethics and education, and productivity researcher of the National Council for Scientific Development (CNPq).

E-mail: rogerio.christofoletti@uol.com.br 